\title{
Artificial Illumination in the Prison: General Recommendation for Prisoner and Associated Staffs
}

\author{
Zeeshan Ahmad Khan ${ }^{1}$ and Asamanja Chattoraj ${ }^{2}$ \\ 'Biological Rhythm Laboratory, Institute of Bioresources and Sustainable Development, Imphal, India \\ 2Department of Animal Science, Kazi Nazrul University, Paschim Brdhaman, Asansol, India
}

The flow of time is unidirectional and none of the present science or any other disciple can make it move otherwise. Therefore, the concept of prison time was developed, which strictly means to lose something which is irreversible, i.e., the time. Apart from time, a prisoner loses his family and carrier. He can always get access to family temporarily in jail and get his carrier back on track after doing time. Nonetheless, he can never get his time back. Currently, for security reasons, the prisoners are kept under longer than the natural illumination or sometimes under continuous illumination. This exposure to continuous light is not only limited to the prisoners, but also to peoples who are innocent until proven guilty in court and the staffs dealing with the prisoners. Recent findings have shown that continuous or long illumination can cause serious behavioural and physiological repercussions including cancer $[1,2]$. The prisoners, apart from time, are also exposed to harmful lighting. Before the light exposure, the law has never subjected prisoners to any other toxicant which are capable to harm the prisoner even after finishing their sentence. In this expression of concern, I would like to recommend a few guidelines to manage the issue of artificial illumination in jail.

1) The prisoners should be exposed to minimum lighting as possible under the security protocol.

2) Low glare and low intensity of bulbs should be put in the

Received: November 1, 2019 Revised: December 7, 2019

Accepted: December 7, 2019

Corresponding author: Zeeshan Ahmad Khan, M.Tech, PhD, Biological Rhythm Laboratory, Institute of Bioresources and Sustainable Development, Takyelpat, Imphal, India.

Tel: 91-873-1867720, E-mail: acezeeshan@live.com

Corresponding author: Asamanja Chattoraj, MSc, PhD, Department of Animal Science, Kazi Nazrul University, Paschim Brdhaman, West Bengal-713 340, Asansol, India

Tel: 91-341-225-2024, Fax: 91-341-227-1024

Email:asamanja.chattoraj@gmail.com

(a) This is an Open Access article distributed under the terms of the Creative Commons Attribution Non-Commercial License (https://creativecommons.org/ licenses/by-nc/4.0) which permits unrestricted non-commercial use, distribution, and reproduction in any medium, provided the original work is properly cited. parts of jail which are responsible for continuous illumination (if not all).

3) Sleep-promoting food such as food rich in melatonin, serotonin, calcium, manganese, and tryptophan, etc. should be included in the prisoner's diet.

4) All the prisoners, proven guilty or pending cases, should be provided with a sleep mask.

5) Weekly evaluation of melatonin level should be done, workers with irregular melatonin level should be given a different duty.

6) All the prisoners with abnormal melatonin should be treated with melatonin.

7) If their situation does not improve, all the prisoners with abnormal melatonin levels should be transferred to the same cell and should be given a normal or close to the normal lighting condition.

\section{Acknowledgments}

None

\section{Conflicts of Interest}

The author has no potential conflicts of interest to disclose.

\section{ORCID iDs}

Zeeshan Ahmad Khan (10)

https://orcid.org/0000-0002-0737-0253

Asamanja Chattoraj (1)

https://orcid.org/0000-0002-8656-7459

\section{REFERENCES}

1. Lee E, Kim M. Light and life at night as circadian rhythm disruptors. Chronobiol Med 2019;1:95-102.

2. Khan ZA, Labala RK, Yumnamcha T, Devi SD, Mondal G, Sanjita Devi H, et al. Artificial Light at Night (ALAN), an alarm to ovarian physiology: a study of possible chronodisruption on zebrafish (Danio rerio). Sci Total Environ 2018;628-629:1407-1421. 